\title{
FREI ANTÔNIO DE SANTA MARIA JABOATÃO, OFM.
}

FREI VENÂNCIO WILLEKE, OFM.

Entre os franciscanos brasileiros do século XVIII, figura Frei Antônio de Santa Maria Jaboatão como um dos mais afamados, em virtude de sua rara inteligência e das primorosas obras que o distinguem. Não obstante isso, são poucos os dados biográficos que seus contemporâneos reuniram e nos transmitiram. Pois, assim como Jaboatão presenciou a era áurea de sua província franciscana, também the assistiu a rápida decadência, a partir de 1763 , quando as leis pombalinas proibiram a admissão de noviços à Ordem de São Francisco, reduzindo até 1779 o número dos professos de 470 que contava em 1763, a 305 e paralisando vários setores do apostolado seráfico.

Encerrando, em 1764 o Orbe Seráfico, Novo Brasílico, o autor franciscano acava de acompanhar a história de sua Ordem, desde os primórdios no Brasil, os quais coincidiam com o descobrimento do País e a primeira missa de Frei Henrique de Coimbra OFM, na Bahia Cabrália, narrando em seguida o progressivo desenvolvimento dêste orbe seráfico que, vencendo todos os contratempos, em meados do século XVIII chegara ao auge de sua gloriosa existência; pois, nessa época, o Brasil-colônia contava aproximadamente 1.200 professos franciscanos agregados a duas províncias autônomas, três comissariados amazônicos e muitos hospícios da Terra Santa ou de Jerusalém. Apenas uma nota destoante quanto à expulsão dos franciscanos de suas missões indígenas de Pernambuco permitia pressentir medidas futuras mais drásticas da parte do governo colonial (1). Mas, antes de as registrar, Frei Jaboatão encerra a "Crônica dos Frades Menores".

(1) - Frei Antônio de S. Maria Jaboatão, OFM Novo Orbe Seráfico Brasílico I \& II Rio de Janeiro 1858-1862, II p. 803 (citado Jaboatão). 


\section{1. - Dados biográficos.}

O pouco que se sabe da octogenária existência de Frei Antônio de Santa Maria Jaboatão não é suficiente para uma biografia completa, mas lembra apenas alguns passos de sua vida religiosa. Francamente, o cronista da província de Santo Antônio que salvou do ingrato anonimato e esquecimento tantos confrades brasileiros e portuguêses, apontando-lhes as obras realizadas, êste benemérito da Ordem Seráfica faria jus a uma minuciosa biografia.

Abordando afinal a vida do cronista franciscano reproduzimos, em primeiro lugar, o que êle próprio publicou no Orbe seráfico (2):

Frei Antônio de Santa Maria Jaboatão, natural deste lugar, freguesia de Santo Amaro, distrito do Recife de Pernambuco, e filho desta província que nela professou, a doze de dezembro de 1717, no convento de Santo Antônio de Paraguaçú, das partes da Bahia, em idade de vinte e dois anos. Concluídos os estudos no convento da Bahia, ficou continuando o ministério da prédica pelo decurso de trinta anos, sendo do permeio destes mestre de noviços no convento de Igaraçú, guardião duas vezes em diferentes tempos no da Cidade da Paraíba, secretário no capítulo do provincial, Frei Manuel de Jesus Maria até a sua congregação e nela prelado local para o convento de Santo Antônio da vila do Recife, definidor no capítulo de 1755 e neste nomeado para cronista da província. Na sua primeira idade, teve gênio e agudeza para a poesia, especialmente a vulgar, de que viu alguns aplausos no estado de secular e no de religioso nos primeiros anos, em que apresentou algumas obras na Academia dos Esquecidos da Bahia (3) assim em abono dos seus presidentes, como em desempenho de assuntos poéticos; mas, desta suave aplicação o divertiram de todo os estudos sagrados, especialmente o da prédica (4), do qual trabalho e aplicação têm saído à luz... (seguem seis obras editadas de 1751 a 1758).

(2). - Jaboatão I, 1 p. 347.

(3). - José Aderaldo Castello, O Movimento Academista no Brasil, $1641-1820 / 22$ vol. I, tomo 1, São Paulo 1969 p. 232-236. O autor indicado como Frè Antônio de Santa Maria vem a ser o próprio Frei Jaboatão. Cf . Arquivo Provincial 160 p. 91-93 (cit'. APR).

(4). - A afirmação de Frei Jaboatão ter cultivado a poesia tão sùmente "na primeira idade" é repetida por vários autores, inclusive Pereira da Costa, - Diocionário Biográfico de Pernambucanos Célebres, Recife, 1882 p. 174, sem no entanto corresponder à verdade; pois, O APR conserva poesias de 1760 a 1768 , entre as 53 existentes (ms). 
Recorrendo a outras fontes completamos os dados acima; Frei Jaboatão nasceu em 1695, filho legítimo do sargento-mor Domingos Coelho Meireles e de Dona Francisca Varela. Com o tio Pe. Agostinho Coelho Meireles, vigário de Santo Amaro de Jaboatão, estudou latim e humanidades.

Como os franciscanos em seus peditórios visitassem frequentes vezes a paróquia de Jaboatão e comó os missionários da mesma Ordem, no incipiente século XVIII, pregassem de lugar em lugar, não faltou ao jovem estudante o ensejo para conhecer os filhos de São Francisco e o vasto apostolado por eles exercido nos cinco conventos do litoral pernambucano e nas aldeias de índios do alto sertão.

Os mosteiros figuravam naqueles idos como centros de cultura, abrigando vários dentre eles, como os de Olinda, Recife e Salvador, cursos de filosofia e teologia para os coristas franciscanos. As atas capitulares da província de Santo Antônio testemunham a cada passo a preocupação dos definitórios pelo progresso e aperfeiçoamento do ensino e pelo aproveitamenot da parte dos coristas (5).

Frei Antônio representa uma das vocações mais pronunciadas porque somente, aos 21 anos de idade, resolveu envergar o hábito seráfico, ao passo que em geral os jovens aos 16 anos já ingressavam na Ordem. O filho de Jaboatão colhera os primeiros aplausos como poeta, antes de rumar ao noviciado. Longe de aspirar a facil glória na flor da idade, preferiu dedicar-se ao profundo estudo filosófico e teológico como à formação religiosa ou conforme êle mesmo confessa, relegou a musa a segundo plano.

Apresentando-se ao Provincial franciscano, Frei Cosme do Espírito Santo, para ingressar na Ordem da Penitência, o candidato teve que seguir para o noviciado de Paraguaçú, no recôncavo bahiano; pois, os aspirantes pernambucanos passavam os sete anos de formação religiosa, na Bahia, e os bahianos, em Pernambuco.

A definitiva admissão ao noviciado dependia do atestado de "limpeza de sangue"; pois, eram recusados os descendentes de judeus, os de côr e até os mestiços. Requeria-se ainda um atestado de conduta e um rigoroso exame de latim (6).

(5). - Atas Capitulares da Província Franciscana de Santo Antônio do Brasil 1649.1893 in RIHGB vol. 286 p. 101 ss (citado $A T A S$ ).

(6) . - Arquivo Histórico Ultramarino, Avulsos de Pernambuco cx. 68 "Relação da Província de Santo Antônio do Brasil" (ms) Entre os candidatos brasileiros à Ordem franciscana que, em 1779, se apresentaram, apenas dois foram aceitos, faltando da parte dos demais ou a limpeza de sangue ou os conhecimentos suficientes do latim. 
Durante o ano de provação, os noviços estudavam a regra e as constituições da Ordem Seráfica, as rubricas da liturgia, as cerimônias do culto e do ofício divinos e o canto gregoriano, submetendo-se a um exame, antes da profissão religiosa. O filho de Jaboatão escolheu o nome Frei Antônio de Santa Maria dos Anjos Jaboatão, omitindo porém "dos Anjos" quasi sempre, nas suas assinaturas. A menção de "Jaboatão" não trai forçosamente o nativismo do frade, mas obedecia a uma tradição antiga, aos poucos abandonada pelos religiosos.

$\mathrm{O}$ ano de provação levou, de 11 de dezembro de 1716 a 12 de dezembro de 1717. Cursaram ao mesmo tempo o noviciado de Paraguaçú Frei Ruperto de Jesus Tôrres o qual, anos depois, ocuparia os cargos de lente de filosofia e teologia em Pernambuco e de ministro provincial na Bahia (7); Frei José de Santa Clara Melo, outro pernambuco que, durante trinta anos, dirigiu a Ordem Terceira Franciscana do Recife (8) e Frei João da Encarnação, posteriormente guardião da Paraíba (9) fora muitos outros cujos nomes e dados exatos ignoramos.

A disciplina regular do noviciado distinguia-se pelo rigor alcantarino, rezando-se o ofício divino não só a certas horas do dia e sim também à meia noite, quando era seguido pela meditação.

O Orbe Seráfico menciona duas vêzes o noviciado do autor:

$$
\text { "quando alí fomos noviço pelos anos de 1717", }
$$

informando que depois da profissão continuou no mesmo convento de Paraguaçú, até agosto de 1718 (10), provavelmente porque o convento de Salvador ainda não comportava o acréscimo dos néo-professos, devido às obras de ampliação do prédio.

Seguiram-se então seis anos de estudos filosóficos e teológicos, no famoso mosteiro bahiano, sede da província de Santo Antônio a qual devia contar, em treze conventos e um hospício, mais de 250 professos que exerciam a catequese dos índios, a assistência religiosa aos africanos importados para as praças de Pernambuco e Bahia, as

(7). - APR 1 p. 161, 162, 164, 209 e APR $20 \mathrm{n}^{9} 806$. - Domingos de Loreto Couto, Desagravos do Brasil e Glórias de Pernambuco in Anais da Biblioteca Nacional, vol. XXIV \& XXV, p. 410.

(8). - Livro $1^{o}$ de Eleições, (Arquivo da Ven. Ordem III de São Francisco do Recife ms), fls. $51-99 \mathrm{v}$.

(9). - Livro dos Guardiães do Convento de Santo Antônio da Paraíba in Revista do PHAN, $\mathrm{n}^{\circ}$ 16, p. 284, (cit ${ }^{\circ} L G P B$ ).

(10). - Jaboatão II, p. 540 \& $544 \mathrm{~s}$. 
missões volantes através dos longínquos sertões, a cura dalmas nas igrejas conventuais e terciárias, o ensino de gramática nas escolas conventuais e o ensino superior nos coristados de Salvador, Olinda e Recife. Vencida a crise interna da província franciscana, que culminaram na desunião dos religiosos, durante a segunda metade do século XVII, notava-se, a partir de 1700 , um franco progresso da vida regular e apostólica dos frades menores.

Conhecemos poucos professores franciscanos que ensinaram a Frei Jaboatão, no convento da Bahia: o religioso bahiano Frei José dos Santos Cosme e Damião, orador sacro afamado, qualificador dos Santo Ofício e lente de filosofia e teologia que chegou a publicar vários sermões em Lisboa (11). Mestre e aluno fizeram parte da Academia dos Esquecidos. A outro professor, Frei Francisco das Chagas, franciscano português, o reconhecido discípulo dedica êstes têrmos elogiosos:

"É sujeito douto na faculdade que professa e em tôdas as mais literárias e especialmente na discursiva, em que a frase é pura, o estilo corrente, os têrmos próprios" (12).

Anos depois, Frei Francisco lecionou teologia no convento de Santo Antônio do Rio de Janeiro, onde saiu eleito provincial da província irmã (13) .

Concluídos os estudos, no ambiente apropriado de disciplina religiosa, e ordenado sacerdote, em 1725, Frei Jaboatão seguiu em agôsto dêsse ano para Olinda (14). Os próximos três decênios de sua vida claustral, Jaboatão os resume no ministério da prédica que, de 1727 a 1730, interrompeu na qualidade de mestre de noviços em Igaraçú-PE e duas vêzes como guardião da Paraíba ou seja de 1741 a 1742 e de 1751 a 1752 oferecendo-nos um rápido aspecto de sua segunda guardiania paraibana, no termo seguinte (15):

"Na congregação que se celebrou no convento da Bahia, aos 29 de maio de 1751, em que presidiu o Padre Frei Gervásio do

(11). - Frei José dos Santos Cosme e Damião, Ternário Concionatório do Seráfico Padre São Francisco, Lisboa, 1745.

(12). - Jaboatão I, 1 p. 355.

(13) . - Frei Diogo Freitas OFM, Elenco Biográfico dos Religiosos antigos da Província Franciscana da Imaculada Conceição do Brasil, Petrópolis, 1931, p. 68ss.

(14). - Cf. nota 25 .

(15). - LGPB n 76. 
Rosário, ministro provincial, foi eleito em guardião dêste convento o irmão pregador Frei Antônio de Santa Maria Jaboatão. Nos onze meses que esteve neste convento, fêz a sacristia nova por detrás da capela [mor] com o salão de cima e via sacra dos terceiros e da mesma parte abriu a porta da capela mor; fêz o arco de pedra da via sacra, mudou o salão do capítulo para a sacristia velha e o que era capítulo se [afundou ao nível da] portaria e no altar desta se pôs a imagem da Senhora Santana que mandou vir da Bahia com esplendor e corôa de prata...".

Da primeira guardiania paraibana de Frei Jaboatão nada consta senão que teve entre seus súditos os lentes Frei Antônio de Santa Maria Traripe (16), Frei Anselmo da Apresentação (17) e Frei André de São Luís (18), êste também autor de vários sermões publicados.

Também a gestão recifense de Frei Jaboatão, de 1754 a 1755 , envolve-se em segredo, sabendo-se apenas que nesse tempo ensinavam, no convento de Santo Antônio, os lentes Frei Boaventura de Santo Tomás, Frei Luís de Santo Antônio, ao mesmo tempo examinador sinodal e notário apostólico (19) e Frei Manuel de Santa Helena (20).

A escolha de Frei Antônio Jaboatão para cronista da província franciscana esclarece do seguinte têrmo das determinações capitulares (21):

"Frei Inácio de São Félix, aos 6 de dezembro de 1755. Determinou-se em mesa pelo definitório e discretório que se elegesse um religioso para cronista desta província, idôneo e capaz, e como tudo isto concorre na pessoa do Irmão Definidor Frei Antônio de Santa Maria Jaboatão o elegemos e nomeamos cronista da província com a obrigação de que, em todos os triênios, dê conta do que tiver escrito; e os irmãos guardiães serão obrigados a the comunicarem as notícias que se lhes pedirem".

O recém-nomeado passou a residir no convento da Bahia, percorrendo porém os conventos em busca de material e elaborando em

(16). — LGPB n' 69. - Jaboatão I, 1 p. 350.

(17). - APR 1 p. 167.

(18). - APR 1 p. 167s.

(19). - Jaboatão $\mathrm{I}, 1$ p. 345 .

(20). - Ibidem.

(21). - APR 1 p. 47. 
menos de dois anos a primeira parte do Orbe Seráfico, Novo Brasilico; pois, em 1757, o autor entregou aos "Superiores o primeiro tomo desta obra para o mandarem imprimir" saindo realmente do prelo em 1761 (22). Como Jaboatão tivesse ocupado o cargo de secretário do provincial, de dezembro de 1752 até junho de 1754 , é provável que nesse tempo já tenha reunido e organizado muito material deixado pelos seus antecessores cronistas, notadamente Frei Luís da Purificação (23) .

A segunda parte da obra pediu um prazo maior até ser encerrada; pois, ao certo o cronista terá principiado esse trabalho, em 1757 , terminando-o tão sòmente em 1764 , sem no entanto ter tido o prazer de ver impresso também o segundo tomo. A partir dessa última data já extinta a Academia dos Renascidos da qual fôra sócio fundador Frei Antônio retirou-se quasi exclusivamente à vida recolhida do claustro bahiano.

A hipótese por muito tempo defendida de ter o nosso cronista imortal falecido, pouco depois de terminado o Orbe Seráfico, foi refutada em 1940, quando se lhe encontrou o termo de óbito (24) que transmite a data real ou seja o dia 7 de julho de 1779 . Foi êsse justamente $o$ ano em que a província franciscana recebeu novos reforços pela admissão dos primeiros noviços desde 1763 , graças a uma licença excepcional concedida pelo governo colonial.

A sepultura de Frei Antônio Jaboatão que ficou provàvelmente no cemitério interno, aberto sob a sacristia e a sala de aulas, entre 1768 e 1771, desapareceu por completo, em fins do século passado, quando se removeram indistintamente todas as ossadas dos ali enterrados para uma cova comum, que existe no canto extremo do quintal, vizinho à sala de aulas.

(22). - Frei Adriano Hypólito OFM, Publicą̧ões de Documentos Históricos - Escritos inéditos de Frei Antônio de Santa Maria Jaboatão in Santo: Antônio 1a. fase ano XVIII $\mathrm{n}^{\circ} 1, \mathrm{p} .71$, (cito Doc. Jaboatão).

(23). - Atas p. 120 (1718).

(24). - APR 20 p. 84-85. No 861 aponta o têrmo de óbito:

"O Irmão Frei Antônio de Santa Maria Jaboatão, natural de Santo Amaro de Jaboatão em Pernambuco, tomou o santo hábito em [17]16 [...] foi passante na congregação de 33 - lente da véspera, Bahia na congregação de 36 - lente de filosofia em 39 [...] - foi porteiro do Recife no Capítulo de 49 e na congregação de 51 Guardião da Paraíba - secretário de Frei Manuel de Jesus em 52 e na congregação guardião do Recife em 54 - porteiro do Recife na congregação de 48 - definidor no capítulo de 55, foi cronista da Província. Faleceu na Bahia a 7 de julho de 1779, sendo guardião Frei Antônio da Encarnação". NB. Os dizeres entre reticências não correspondem à verdade. Trata-se aqui de uma cópia precipitada do ano de 1810 e feita por Frei Sebastião de Jesus e Santana. 
Sôbre a vida religiosa de Frei Jaboatão nos faltam detalhes. Mas, o fato de ter ocupado o cargo de mestre de noviços, aos 32 anos de idade, demonstra que o jovem franciscano levava a sério o ideal seráfico e o cumprimento dos seus deveres religiosos; pois, se assim não fôsse, outro mais merecedor teria recebido o posto de tanta responsabilidade.

Mas, o temperamento dêste jovem mestre era alegre, segundo demonstra uma carta que, aos 30 anos de idade, escreveu em Olinda, recém-chegado, contando as primeiras impressões do novo ambiente a um confrade e colega de estudos. Os numerosos trocadilhos e jogos de palavras espelham-lhe o temperamento jovial. Sem querer desprestigiar Pernambuco, sua terra natal, Frei Jaboatão espontâneamente terá confrontado Olinda com a Cidade do Salvador, onde pelo espaço de sete anos presenciara o fausto do ouro, o luxo da capital e a vida acadêmica dos Esquecidos, enquanto Olinda aos poucos cedia o seu prestígio ao vizinho Recife. Eis o teor da missiva característica (25):

"Cheguei ao Convento do Recife, véspera de São Bartolomeu (26), e com pouca detença nele, passei a este da Cidade. O que nela vi primeiro que tudo, foi a ponte do Varadouro (27), e se hei de dizer verdade, foi a primeira vêz que a vi, e bem posso dizer que depois que a vi, estando ainda no rio ao tomar do pôrto ficamos eu e mais a canoa,ela varada e eu passado; depois de termos ambos andado às varas.

Cheguei ao Convento, e assim como the pus os pés, logo lhe debuxei a planta. Jaz em lugar fresco e lavado dos ventos pela parte do mar; e por cima das águas que caem do colégio (28) tão eminente nos fica este que quando the lanço os olhos, parece-me, e será a primeira vez, que se deixam ver botas sobre tamancos e barrete em cabeça de capucho. Entre êstes dois, fica a si desviada algum tanto à parte do poente. Ali me pus também a horas que rezavam vésperas os reverendos Cônegos. Entre todos eram dois, e az: em duas fileiras ou cordas, desejei dar-lhe um par, e meio de nós a ver se cresciam mais em número, mas, logo pelo que êles rosnavam alcancei, que sendo dois e az, já tinham os nós.

(25). - A carta aperece sob o n" 10 das "Obras Acadêmicas" in APR 160.

(26) . - Lê-se à margem "de 1725 ". Frei Jaboatão chegou pois ao Recifc a 23 VIII. 1725. - Doc. Jaboatão 2 p. 140.

(27) . - Como novidade inaudita, a ponte do Varadouro estava em foco. Cf. Galanti, História do Brasil, São Paulo, 1902, III $n^{\circ} 106$.

(28) . - O colégio vem a ser o dos Jesuítas tendo servido posteriormente de seminário diocesano. 
Tem a sé cinco naves de obras perfeitas, porque se obras da sé se chamam aquelas, que não estão acabadas de todo; é o que nesta sé não há, porque as suas obras de todo estão bem acabadas. À nossa mão esquerda estão os Carmelitas e Bentos; e tive por novidade nos cedessem aqui o seu direito; pois, em tudo nos querem levar a mão, mas é porque aqui não são só êles os que têm mão para tudo. Contudo, eu entre êles aqui fico nesta linda cidade, quero dizer de Olinda. Não me tem parecido mal; porque tudo nela é bem parecido. E assim me quer parecer razão não faça eu alguma cara má, a quem me mostre tão bôas caras; e galanteria é que sendo tudo isto tão digno de ser claro, não é tão caro, como isso. E o que merece mais estimação é que quando se dão estas coisas mais de graça, então mostram que não têm preço.

Pelas ruas não há ver pé de gente, e se acaso alguma se encontra é gente de pé. Não lhe faltam ruínas nos edifícios, sendo que nos mais dêles, eu vi frontespícios perfeitos. As mais das casas deram com o corpo em terra, mas entre alguns pedaçus de paredes, se divisam ainda pendentes alguns painéis que entre aquêles caídos, movem as tenções e abalam os espíritos.

Finalmente se no mundo há Paraíso terrestre, dizem muitos ser êste o Paraíso do mundo, não só pela variedade dos pomos e o galante das frutas, mas sim porque se beatas no Paraíso se dizem as almas, as almas dêste Paraíso não deixam de ser beatas; e por isto na sua cultivação crescem os devotos, as orações e deprecações se multiplicam; e porque são bem despachadas, tôdas ficam justas; e eu também aqui fico (29) porque ainda que tenha mais por que discorrer, não tenho agora lugar para mais.

Frei Antônio de Santa Maria Jaboatão".

\section{2. - Obras de Frei Jaboatão.}

Se as obras de Frei Jaboatão se salvaram é porque êle conseguiu ainda em vida a publicação do Novo Orbe Seráfico (primeira parte), e de vários sermões, chamando a atenção do público para o seu raro talento. Ao contrário do que alguns autores afirmam, o franciscano não destruiu os originais de suas poesias, mas confiou-os ao arquivo provincial franciscano da Bahia, onde também a segunda parte do Novo Orbe Seráfico ficou até 1840 , quando o manuscrito passou para o

(29). - Em seguida, acrescenta: "Aqui fico, não em via unitiva, porque ainda não entrei na purgativa, suposto tenha às vêzes meus atos de contemplativo...". 
Instituto Histórico e Geográfico Brasileiro, visto que as tipografias da Bahia não garantiam bôa impressão.

Ignoramos os motivos por que, depois de 1761 , não se publicou trabalho nenhum do nosso autor, embora o Provincial Frei Jacinto de Santa Brígida desse ordens neste sentido, durante a gestão de 1764 a 1768, segundo reza a advertência escrita na folha de rosto do Novo Orbe Seráfico conservado em ms no IHGB. Desde que o Marquês de Pombal proibira a admissão de noviços às Ordens religiosas do Brasil (1763), cessavam também as graças régias por mais que Frei Jaboatão procurasse merecê-las, com poesias dedicadas a $\mathrm{D}$. José I e ao seu ministro "onipotente".

Durante os anos de seu sacerdócio, o nosso cronista se destacava pelos sermões e discursos pronunciados e publicados, pelas poesias recitadas nas Academias dos Esquecidos e dos Renascidos como também nas comunidades franciscanas, mas principalmente pela obra que mais o celebrisou, o Novo Orbe Seráfico Brasílico. Com a morte dêste famoso franciscano, também a sua província ia decaindo a largos passos, explicando-se assim o esquecimento quasi total que o tão festejado frade experimentou, durante longo tempo.

\section{a). - Inéditos de Frei Jaboatão.}

Os inéditos que somam mais de cem, como sejam cartas, poesias, discursos etc. vão reunidos num volume intitulado (30):

\footnotetext{
"Obras Acadêmicas e outras várias, prosas e versos, feitas e recitadas na Academia Brasílica dos Renascidos, instituida pelo Conselheiro José Marcarenhas Pacheco Pereira Coelho de Melo, cebrada (sic) a sua primeira conferência pública em 6 de junho, dia em que fazia anos o fidelíssimo Rei e Senhor D. José I. no de 1759. Por Frei Antônio de Santa Maria Jaboatão, Pregador, ex-Definidor, Cronista da Província de Santo Antônio do Brasil, da qual é filho e natural de Santo Amaro de Jaboatão, em Pernambuco, e Acadêmico numerário da Academia dos Renascidos".
}

Entre todos os manuscritos desta coleção merece menção especial um estudo jurídico, incluído sob o $\mathrm{N}^{0} 86$, por demonstrar a imparcialidade de Jaboatão e sua franqueza para com os confrades que então governavam a província franciscana. Eis o título:

(30). - APR 160. 


\begin{abstract}
"Manifesto da razão pela qual se mostram por discursos sujeitos ao entendimento, vencidos dos ditames livres da vontade, com que obrou esta, no caso proposto da substituição de um vogal para o difinitório do Capítulo da Província de Santo Antônio do Brasil de dois de dezembro de 1758. Por um dos seus filhos independente e desinteressado. Frei Antônio de Santa Maria Jaboatão".
\end{abstract}

Ao ensejo do referido Capítulo Provincial, Frei Jaboatão como definidor era um dos vogais. Falecido, pouco antes do Capítulo, o Pe. Definidor Frei Constantino de São Lourenço, devia ser subrogado o Padre mais digno da Província, criando-se em tôrno da escôlha duas opiniões diferentes, uma a dos "Padres do govêrno" firmada no estatuto provincial, a favor do ex-provincial Frei João da Trindade, outra alegando o mesmo estatuto provincial, as constituições da Ordem Franciscana e decretos pontifícios, a favor do ex-definidor geral Frei Inácio das Neves. Jaboatão defendia esta segunda opinião, ao passo que foi subrogado Frei João da Trindade.

Passados meses após o Capítulo, o autor do manifesta acrescentou a êste os dizeres:

"Foi anulado êste Capítulo e depois sarado, para evitar inconsequiências, pelo Nosso Revmo. Pe. Comissário Geral Frei Pedro João de Molina por umas letras circulares suas de 29 de março de 1759, fundadas nas mesmas razões que aqui se alegam dos Estatutos Gerais; e ficou o sobredito ex-definidor geral gozando a preeminência de Padre mais digno da Província".

b). - Obras publicadas de Jaboatão.

Ainda em vida do autor (1751-1758), sairam do prelo seis discursos, sermões e tratados, merecendo destaque o sermão de Santo Antônio pronunciado em 1731 na festa de Corpo de Deus no convento do Recife, para solenizar a efeméride da restauração de Pernambuco (1654) . Os sermões e discursos foram pronunciados em Pernambuco e na Paraíba, quando da segunda guardiania de Jaboatão de 1751 a $1752(31)$.

O Catálogo Genealógico da autoria do nosso cronista saiu do prelo em 1889 (32) devendo datar o manuscrito de época posterior a

(31) . - A fôlha de rosto menciona especialmente que o orador era, na ocasião, guardião da Paraíba. - LGPB, $\mathrm{n}^{\circ} 76$.

(32). - Frei Antônio de Santa Maria Jaboatão, Catálogo Genealógico in Revista Trimestral 52 I (Rio 1889). 
1757; pois, deixa de figurar entre as obras impressas e manuscritas de Jaboatão que se acham enumeradas na primeira parte do Novo Orbe Seráfico.

A obra mais importante do nosso autor é, sem dúvida, o Novo Orbe Seráfico, por ser a única a registrar a origem e o desenvolvimento da Província de Santo Antônio do Brasil, através dos seus 14 conventos, incluido também as missões esporádicas mantidas pela Ordem Franciscana, de 1500 a 1584, e os primórdios das missões amazônicas a partir de 1617, como ainda as primeiras fundações franciscanas, entre o Espírito Santo e São Paulo e que em 1659 passaram a formar nova custódia e em 1675, prmoveram à categoria de província autônoma, sob o título da Imaculada Conceição e com sede no Rio de Janeiro.

Ao invez da historiografia moderna e exata, Frei Jaboatão aceita e aproveita dados incertos, lendas e tradições regionais. Haja vista a fantasiosa descrição com que o nosso cronista provincial tenta encher as lacunas que a história deixou, no caso dos protomártires franciscanos de Pôrto Seguro (33).

Em parte se compreende a pressa de Frei Jaboatão - entrementes sexagenário - em terminar e entregar ao prelo uma obra que antecessores como Frei Luís da Purificação, durante decênios não conseguiram realizar, ao passo que o autor do Novo Orbe Seráfico gastou menos de dois anos para compor a primeira parte, embora baseado nos estudos dos confrades cronistas anteriores.

Mas, justamente a segunda parte do Novo Orbe que levou quase sete anos até o término reclama aqui e acolá dados mais minuciosos; assim por exemplo as missões entre os índios, regidas pela Província de Santo Antônio, desde 1679, mereciam mais destaque, de vez que o arquivo provincial da Bahia dispunha de abundante material. Enquanto a fase missionária da custódia (1585-1619) é tratada com muitos detalhes, as missões da Província ocupam menos de três páginas (34).

A interpretação dos acontecimentos adotada por Frei Jaboatão recorre, segundo o modo dos antigos, a milagres e outros fatos extraordinários, chocando o leitor do século XX. Basta porém manusear-

(33). - Jaboatão I, 2 p. 11-15. - Frei Odulfo van der Vat OFM, Princípios da Igreja no Brasil, Petrópolis, 1952, p. 39. O saudoso Frei Odulio submete a rigoroso exame os vários grupos de missionários franciscanos apontados por Jaboatão, entre 1500 e 1584 , como também impugna a existência de uma Ordem Terceira Franciscana secular em Olinda, durante o século XVI, tão ardorosamente defendida por Jaboatão.

(34) . - Jaboatão II, p. 801-803. 
mos os documentos oficiais do govêrno colonial a respeito das promoções de Santo Antônio para descobrirmos o conceito do sagrado que naqueles idos se aplicava na esfera do profano.

Em vida do autor, saiu do prelo a primeira edição parcial, em Lisboa no ano de 1761, levando o título Orbe Seráfico, Novo Brasílico, seguindo-se a primeira edição completa, no Rio de Janeiro, de 1858 a 1862 sob o título Novo Orbe Seráfico Brasílico. A nova edição que está sendo preparada voltará ao título original.

\section{3. - Frei Jaboatão, Abridor de Chapas.}

O Pai da História Pernambucana, Francisco Pereira da Costa (35) apoiado em Domingos de Loreto Couto, (36) afirma que

"Frei Antônio de Santa Maria Jaboatão tinha grande destreza em abrir sutis estampas e primorosas imagens ao buril e rara habilidacie para exercitar tôdas as artes e era insigne em formar os caracteres para os livros de côro, debuchando com a pena, como se fôra pincel, as letras iniciais e iluminando-as com ouro e diversas côres".

Referindo-se ao informe acima, pondera o Prof. Marcelo Ipanema (37):

"Teria dado maior consequiência à sua arte o escritor religioso do século dezoito? Como e quem, se houve, ensinou ao frade a arte de gravatar? Não é descabida a hipótese, por enquanto, de que civis e religiosos, êstes principalmente, conhecessem e usassem em seu ministério, como de Loreto Couto se pode inferir, atividades gráficas ou artes a elas ligadas".

Ainda que os arquivos franciscanos nada refiram a respeito de tantas habilidades do nosso cronista provincial fazemos nossas as ponderações do Prof. Ipanema, visto que Frei Jaboatão até à idade de 21 anos, quando entrou na Ordem, já pode ter aprendido as referidas artes, no Recife, ou a partir de 1718 , quando de seus estudos superio-

(35). - F. A. Pereira da Costa, Estudo histórico retrospectivo sôbre as artes em Pernambuco in Revista do IAHG-PE, vol. IX, $\mathrm{n}^{\circ} 54$ p. 3-45.

(36) . - Domingos de Loreto Couto, op . cit., p. 366, $\mathrm{n}^{\circ} 20$.

(37). - Marcelo e Cybelle de Ipanema Estabelecimento da Tipografia $e$ Origem do Jornalismo no Brasil in Revista Brasileira de Comunicação, Ano I, $\mathrm{n}^{0}$ 1, (Brasília, março de 1968), p. 84s. 
res no convento da Bahia. Pois, na capital do Brasil-colônia, as Ordens religiosas e Irmandades porfiavam em primar pela arte sacra em suas igrejas e claustros, sobressaindo entre todos o templo magestoso de São Francisco.

\section{Epílogo.}

Neste resumo, nos limitamos às linhas gerais da biografia de Frei Jaboatão e à rápida apreciação de suas obras, baseando o estudo sôbre as fontes franciscanas coevas, sem refutar todos os autores que, de qualquer modo, se equivocaram com fatos e datas importantes da vida do nosso cronista provincial. Por incúria dos nossos antepassados, ficam grandes lacunas que provàvelmente jamais cobriremos. Assim por exemplo de 1730 a 1741, ignoramos tanto a residência do pregador Frei Antônio, como ainda os detalhes de suas atividades, exceto o sermão de Santo Antônio pregado, em 1731, na igreja conventual do Recife: Igualmente não podemos acompanhar a velhice de Frei Jaboatão, a partir de 1764, sabendo ùnicamente que, até 1769 , ainda se dedicava às musas.

Por felicidade, desfrutamos das obras e até de muitos inéditos que o público reputava perdidos. 


\section{APENDICE.}

\section{INDICE DAS "OBRAS ACADEMICAS".}

Dado o raro valor das Obras Acadêmicas da autoria de Frei Jaboatão reproduzimos a seguir o índice de todos os documentos que, com poucas exceções, continuam inéditos no arquivo do provincialado franciscano do Recife (1).

O formato do manuscrito de 248 páginas é de $200 \times 390 \mathrm{~mm}$. A ação do tempo e da traça afetou principalmente a legibilidade das palavras próximas às margens das fôlhas. A paginação ficou incompleta, faltando nas primeiras 52 páginas e nas 121 últimas e principiando, após as 52 páginas iniciais, com o n. 91 para terminar com o n. 164 . Adotamos para melhor clareza uma paginação completa, assinalada com asterisco $\left({ }^{*}\right)$, começando o índice com o n. 1, a partir da fôlha de rosto. A paginação original de Frei Jaboatão (cf. n. 6) figura, em parênteses.

1). - pág. 1* título do volume: OBRAS ACADEMICAS... Página $2 *$ em branco.

2). - p. $3 *-6 *$ dedicatória ao Dr. José Mascarenhas Pacheco Coelho de Mello, diretor da Academia dos Renascidos da Bahia.

3). - p. $7 *-10 *$ diploma da entrada de Jaboatão para a citada academia, com assinaturas do diretor, censores e secretário e com o sêlo acadêmico.

4). - p. $11 *-44 *$ trabalhos acadèmicos e temas para as diversas conferências da academia (2).

5). - p. $45^{*}-52 *$ cópia dos "breves pontifícios e ordens reais, com que se instituiram adiministradores, nas partes do Rio de Janeiro e Pernambuco". a). — breve de Gre-

(1). - Doc. Jaboatäo in Santo Antônio XVIII \& XIX inclui vários produtos literários de Jaboatão.

(2). - Cf. acima II, 1 Inéditos, onde se trata das Memórias, em parte a cargo de Jaboatão, Frei Bento da Apresentação e Fr. José do Santos Cosme e Damião. 
gório XIII instituindo administrador para o Rio de Janeiro (1575); b). - breve de Paulo V instituindo o de Pernambuco $(1614) ; c)$. - aprovação do $\operatorname{Rei}(1615)$.

6) . - p. 53*-55* (pág. 91-93-Jab.) "romance feito na Academia dos Esquecidos que no seu palácio instituiu o Vice-Rei Vasco Fernandes Cesar, na Bahia no ano de 1723, sôbre o assunto lírico: Qual foi mais amante, se Clice do Sol, ou Eudemião da Lua. Resolve por êste o romance". Com assinatura de Fr. A. Jaboatão.

7). - 56* (Jab. 94) décima e logo em seguida: "resposta do autor". Ambas aparecem depois ( $n^{\circ} 53$ ).

8) - - p. 57* (Jab. 95) duas décimas: "à morte de um cavaleiro nobre chamado Luís, irmão de Henrique Luís, Governador de Pernambuco, nas exéquias que ali lhe fêz". Data: 1739. Fr. A. Jaboatão.

9). - p. 58* (Jab. 96) "décima a um requerente que presumia de poeta, presidindo em uma academia particular jocosa que se fêz em Pernambuco, chamado Luís". Assina "Fr. A. Jaboatão".

10). - p. 59* (Jab. 97s) "carta escrita de Olinda a um companheiro que foi de estudo na Bahia" 1725.

11). - p. 61*-62*(Jab. 99s) 7 décimas ao sargento mor Jorge Carreira Miranda, ex-ministro da Ordem IIr. de São Francisco do Recife. 1749. Assinatura: Bato Jama $=$ Jaboatão.

Em seguida, vai a resposta às 7 décimas supra assinada por Cas J[O]NS (?) .

12) - - p. 63*s. (Jab. 101s) "Loas para la comédia: Amor y obligacion", em espanhol. Parece tratar-se de uma festa em honra ao P. Visitador Frei José de Sta. Maria Colares; data 1731. "Fr. A. Jaboatão".

13) - - p. 65*s (Jab. 103s) ofício da Câmara do Recife solicitando o parecer de Fr. Jaboatão, quando presidente in cápite do convento de Stọ. Antônio do Recife. 9 de dezembro de 1749 .

14). - p. $67 * \mathrm{~s}$ (Jab. 105s) resposta ao ofício supra. 12 de dezembro de 1749. Frei Antônio de Sta. Maria Jaboatão. Pres. in cápite.

15). - p. 68* (Jab. 106) décima "a uma pessoa douta que esperando do autor, sendo guardiaão do Recife, um ramalhete por festa da Páscoa [1755]. ." Assina "Frei A. Jaboatằ".

16). - p. 69*s (Jab. 107s) ofício de D. Fr. Luís de S. Teresa, bispo de Olinda a Fr. Jaboatão quando presidente in cá- 
pite, convidando-o a tratar de uma questão que havia com as autoridades civis. 10 de dezembro de 1749 .

17). - p. 71 *s (Jab. 109s) Parecer de Fr. Jaboatão favorável ao bispo. "Convento de S. Antônio do Recife, 20 de dezembro de 1749. Frei Antônio de S. Maria Jaboatão. Prelado.." p. 73*s em branco.

18). - p. 75* (Jab. 113) soneto "ao sr. diretor ... no dia 6 de junho de 1759 , recitando a primeira oração de abertura da Academia [dos Renascidos]". Assina Fr. Jaboatão.

19). - p. 76*ss (Jab. 114-116) 6 décimas "ao mesmo diretor".

20). - p. 76* (Jab. 116) soneto "por escapar S. Magestade da inundação, terremotos e fogo de assassinos". Fr. Jaboatão.

21). - p. 79*s (Jab. 117s) mote e glosas "[nos] claríssimos anos de nosso augusto monarca D. José I"; repetida no "Congresso geral de 6 de junho". Frei A. Jaboatão.

22). - p. 81*s (Jab. 119s) 4 décimas "ao Sr. Sebastião José de Carvalho e Mello etc. DD. Mecenas da nova Academia dos Renascidos no Brasil...". Frei A. Jaboatão.

23) - - p. $83^{*}-100^{*}$ (Jab. 121-138) "dissertação primeira que se deu na Academia dos Renascidos do Brasil, para o dia 21 de julho de 1759 e se repartiu na conferência antecedente de 7 do mesmo mês". 19. quesito: "Se há na na América a planta sensitiva". 2\%. quesito: "Se é certo produzir-se também na América a herva que abranda o ferro como afirma certo. autor. ." Jaboatão figura entre os oradores, com outros três.

24) . - p. 101\%-105* (Jab. 139-143) "conta dos estudos acadêmicos" defendendo a primazia dos Franciscanos como missionários do Brasil. O estudo é assinado por "Fr. Antônio de S. Maria Jaboatão". p. 106*-108* em branco.

25). - p. 109*-111* (Jab. 147-149) "Aprovação a uma obra da Academia dos Renascidos". as. Fr. A. Jaboatão. p. $112 *$ em branco.

26) . - p. $113^{*} \mathrm{~s}$ (Jab. 151s) mote e glosas "aos augustos e felicíssimos anos de S. A... a Princesa do Brasil. Na Academia de 17 de dezembro de 1759". Assina "Frei A. Jaboatão" .

27). - p. 115* (Jab. 153) soneto ao Vice-Rei, Marquês do Lavradio. 1760. as. Fr. A. Jaboatão.

28) . - p. 116* (Jab. 154) décima "ao mesmo assunto". as. Fr. A. Jaboatão. 
29). - p. 117* (Jab. 155) 2 décimas "ao Sr. João Borges" substituto do diretor da academia. 17[59]? as. Fr. A. Jaboatão.

30). - p. 118* (Jab. 156) décima "à morte do acadêmico numerário o $\mathrm{R}\left[\mathrm{ev}^{9}\right]$. Antônio de Oliveira. Faleceu na Jacobina em visita neste ano de 1760 ". as. "Fr. A. Jaboatão".

31). - p. 119*-121* (Jab. 157-159) ) carta ao cônego José de Oliveira Bessa, datada em 12 de fevereiro de 1761. as. Fr. Antônio de S. Maria Jaboatão. - p. 122* em branco.

32). - p. $123 *-125 *$ (Jab. 161-163) carta ao cônego Antônio Gonçalves Pereira, datada e assinada: "Bahia 1762. Fr. Antônio de S. Maria Jaboatão" . - - p. 126* em branco.

33). - p. $127 *-129 *$ carta a um cônego, sem dizer o nome. p. $130 *$ em branco.

34). - p. 131* soneto ao governador da Paraíba, Jerônimo Jorge de Melo e Castro.

35). - p. 131* décima "ao mesmo assunto". as. Fr. Jaboatão. $\mathrm{O}$ assunto do soneto e da décima é quasi o mesmo que o dos $n^{\circ}$ s. 27 e 28.

36). - p. 132* "Ao mesmo outro soneto".

37). - p. 132" "Ao mesmo, décima". as. "Fr. Jaboatão".

38) - - p. $133 *$ mote e glosas ao Rei D. José I. - p. $134 \%$ em branco.

39). - p. 135 " mote e glosas "ao Menino Deus nascido no presépio". p. 136* em branco.

40). - p. $137 *$ soneto ao Marquês do Lavradio pelo aniversário. 1768 .

41) . - p. $138^{*}$ mote e glosas em homenagem ao mesmo.

42) . - p. 139* décima anagramática em tôrno de "Luís" (Marquês do Lavradio) e "luz".

43). - p. 139" "Outro ao mesmo conceito". N's. 42 e 43 são iguais ao $\mathrm{n}^{\mathrm{9}} .8$.

44) . - p. 140* 2 décimas em homenagem ao marquês do Lavradio.

45). - p. $141^{*}$ mote e glosas oferecidos ao mesmo.

46). - p. $142^{*} 2$ décimas ao mesmo.

47). - p. 143* 3 décimas ao mesmo ào ensejo das núpcias de duas filhas.

48). - p. 144* 3 décimas ofertadas: ao governador José da Cunha Ataíde, conde de Povolide, no dia natalício, 25 de junho de 1770 , Bahia. 
49). - p. 145*-150* "Advertência". Introdução ao "Jaboatão místico em correntes sacras dividido" que vem a ser uma coleção de sermões.

50). - p. $151 *-153 *$ oferecimento de "um livrinho" ao visitador geral Fr. Manuel de Jesus Maria cujo secretário fôra Jaboatão, em 1752. "Convento de S. Francisco da cidade da Bahia, 4 de julho de 1758. Frei Antônio de S. Maria Jaboatão, ex-definidor e cronista".

51). - p. 157 * breve notícia sôbre o noviciado da Companhia de Jesus, na praia de Jequitaia.

52). - p. 157 * s notícia sôbre o recolhimento da Solidade, na Bahia.

53) . - p. 159* décima satírica de certo poeta e resposta satírica de Jaboatão, 1720 . No 53 é igual ao $\mathrm{n}^{0} 7$.

54). - p. 160* décima ou "epitáfio a dois amigos fazendo um ... as exéquias do outro...".

55). - p. $161 *-165 *$ aprovações feitas ao volume de sermōes de Jaboatão (cópia) a mandado da Academia, com data de 4 de agosto de 1759 . p. $166^{*}$ em branco.

56). - p. $167 *-168 *$ aprovação dada por ordem do Provincial a uns cadernos de sermões compostos e pregados por Fr. José dos SS. Cosme e Damião. Bahia, 23 de maio de 1763. Fr. Antônio de S. Maria Jaboatão, ex-definidor e cronista.

57). - p. 169* aprovação especial dos sermões supra. . .. maio de 1763. as. Fr. Antônio Jaboatão. (fôlha truncada) . p. $170^{*}$ contém, como fôlha truncada, um fragmento de discurso, quasi igual ao $\mathrm{n}^{9} 63$.

58). - p. $171^{*}-174^{*}$ aprovação dada por ordem do Provincial a um estudo do Irmão corista Fr. Raimundo de S. Teresa, que defendo $S$. Boaventura. Bahia, 12 de agôsto de 1757. Fr. A. Jaboatão.

59) . - - p. $175 *$ s dedicatória de um sermão pregado em ação de graças por ter saido incólume $D$. José $I$ de um atentado. "Fr. Jaboatão" e "Os oficiais da Câmara da Vila da Jacobina" (BA).

60) . - p. $177^{*}$ s dedicatória de outro sermão pelo mesmo motivo. "Fr. Jaboatão".

61). - p. 179 *s dedicatória a El-Rei, para um sermão de casamento da nossa princesa com o Infante D. Pedro. "Fr. Jaboatão" e "Os camaristas da vila de Jacobina".

62) . - p. $181^{\text {*s }}$ aprovação do "Orbe Seráfico Novo Brasílicu" feita por Fr. Manuel Pinto de Jesus Maria, por ordem 
da academia. "Carmo da Bahia, 2 de agôsto de 1759. Fr. Manuel Pinto de Jesus Maria".

63). - p. $183^{*}-190$ * oração acadêmica ao ministro ouvidor, José Joaquim de Almeida e Araújo: 1769.

64) : - p. 191*-197* oração acadêmica e genetlíaca. Fr. Antônio Jaboatão. p. $198^{*}$ em branco.

65). - p. 199* soneto "para um nascimento..".

66). - p. 199* soneto ao mesmo assunto. "Fr. Jaboatão".

67) . - p. 200* mote e glosa ao dito assunto. "Fr. Jaboatão".

68 ). - p. 201* décima a um acadêmico chamado Antônio.

69). - p. 201* décima a Antônio da Silva.

70) . - p. 201* décima a João Pereira do Nascimento. "Fr. Jaboatão".

71) . - p. 202* décima a João Batista Nogueira.

72). - p. 202 * décima "à parteira que vendo o menino nascido lhe deu um apertucho de amor".

73). - p. 202* décima "a um anão e uma velha amantes". "Fr. Jaboatão".

74) . - p. 203* motes e glosas. "Fr. Jaboatão".

75). - p. 204* décima a uma velha preta que servia de divertimento.

76). $\rightarrow$ p. $204 *$ décima.

77.) - - p. 204* décima.

78). - p. $205^{*}$ mote e glosas pelo nascimento de uma criança. "1764".

79). - p. 205* décima " a um anão e uma velha". Igual a n 73 supra. "Fr. Antônio Jaboatão".

80 ). - p. $206^{*}$ soneto pelo nascimento de uma criança (do n' 78).

81). - p. $206 * 2$ oitavas ao mesmo assunto.

82). - p. $207^{*}$ soneto a Francisco Marcelino de Gouveia .

83). - p. $207^{*}$ décima satírica a um "reverendo defendente".

84). - p. $207 *$ décima satírica a Romão.

85). - p. 208* mote e glosas.

86). - p. $209 *-230 *$ manifesto da razão, a favor de um confrade que deveria ter entrado como suplente no capítulo provincial de 2 de dezembro de 1758. "Por um dos seus filhos independente e desinteressado: Fr. Antônio de S. Maria Jaboatão". (Em várias páginas, o autor intercalou aditamentos).

87) . - p. $231 *-244 *$ (em branco pp. $235^{*} \& 236^{*}$ ) conferência sôbre o tema: "Qual é a empresa de maior glória: celebrar Lisboa a conservação da vida d'El-Rei Fide- 
líssimo D. José $\mathrm{I}$, na sua presença ou celebrá-la a Bahia na sua ausência"? Da Academia dos Renascidos.

88) . - p. $245^{*}$ notícia sôbre a imagem de St Antônio de Arguim (resumo do "Urbe Seráfico" II p. 80ss). Na mesma página, há uma nota sôbre casos de conciência .

p. 246* com uma só frase.

p. $247^{*}$ receita de remédio caseiro - citações religiosas. "Frei Antônio de S. Maria Jaboatão".

p. 248* sentença de São João Crisóstomo - versos latinos - metodo "para saber-se em que dia da semana entra o mês".

É provável que Frei Jaboatão tenha legado à posteridade muitos outros escritos que não mereceram o mesmo carinho dos arquivistas que as Obras Acadêmicas. Pois, o nosso cronista passou em Salvador os últimos 24 anos de vida (1755-1779) prazo que sem dúvida aproveitou, máxime após ter entregue a 2a. parte do Orbe Seráfico, em 1764. Os derradeiros produtos literários conhecidos e conservados datam de 1768 a 1770 (cf. n.os 40, 48 \& 63), quando o autor beirava os 75 anos de idade. 